\title{
Concentrative nucleoside transporter 3 as a prognostic indicator for favorable outcome of $t(8 ; 21)$-positive acute myeloid leukemia patients after cytarabine-based chemotherapy
}

\author{
JU HAN SONG ${ }^{1}$, KYUNG-MIN CHO ${ }^{1}$, HYEOUNG-JOON KIM ${ }^{2}$, YEO-KYEOUNG KIM ${ }^{2}$, NAN YOUNG KIM ${ }^{2}$, \\ HEE-JE KIM ${ }^{3}$, TAE-HYANG LEE ${ }^{3}$, SEUNG YONG HWANG ${ }^{4}$ and TAE SUNG KIM ${ }^{1}$ \\ ${ }^{1}$ Division of Life Sciences, School of Life Sciences and Biotechnology, Korea University, Seoul; \\ ${ }^{2}$ Genome Research Center for Hematopoietic Diseases, Chonnam National University Hwasun Hospital, Hwasun; \\ ${ }^{3}$ Catholic Blood and Marrow Transplantation Center, Seoul St. Mary's Hospital, The Catholic University of Korea, Seoul; \\ ${ }^{4}$ Division of Molecular and Life Science and GenoCheck Co., Ltd., Hanyang University, Ansan, Republic of Korea
}

Received January 20, 2015; Accepted March 18, 2015

DOI: $10.3892 /$ or.2015.3959

\begin{abstract}
Although acute myeloid leukemia (AML) exhibits diverse responses to chemotherapy, patients harboring the $t(8 ; 21)$ translocation are part of a favorable risk group. However, the reason why this subgroup is more responsive to cytarabine-based therapy has not been elucidated. In the present study, we analyzed expression levels of cytarabine metabolism-related genes in patients diagnosed with AML with or without $t(8 ; 21)$ and investigated their correlation with clinical outcomes after cytarabine-based therapy. Among the 8 genes studied, expression of the concentrative nucleoside transporter 3 (CNT3) gene was significantly higher in $\mathrm{t}(8 ; 21)$ positive patients compared to the others in the test population and the validation cohort $(\mathrm{P}<0.001$ in Mann-Whitney $\mathrm{U}$ test; $\mathrm{P}<0.002$ in Pearson's correlation analysis). Additionally, in both multivariate and univariate analyses, $\mathrm{t}(8 ; 21)$-positive patients categorized in a higher CNT3 expression tertile had longer disease-free survival [hazard ratio (HR), 0.117; 95\% confidence interval (CI), 0.025-0.557; $\mathrm{P}=0.008$ ] and overall survival (HR, 0.062; 95\% CI, 0.007-0.521; $\mathrm{P}=0.010$ ) compared to $\mathrm{t}(8 ; 21)$-positive patients in a lower $C N T 3$ expression tertile. Notably, these trends did not occur in $\mathrm{t}(8 ; 21)$-negative patients. Our results demonstrate that CNT3 expression is associated with overall favorable outcomes and is predictive of clinical outcomes in AML patients with $\mathrm{t}(8 ; 21)$. This suggests that CNT3 expression can be used to optimize treatment strategies for AML patients.
\end{abstract}

Correspondence to: Dr Tae Sung Kim, Division of Life Sciences, School of Life Sciences and Biotechnology, Korea University, 5-ga, Anam-dong, Seongbuk-gu, Seoul 136-701, Republic of Korea

E-mail: tskim@korea.ac.kr

Key words: acute myeloid leukemia, CNT3, cytarabine, t(8;21) translocation, prognosis

\section{Introduction}

Acute myeloid leukemia (AML) is a highly heterogeneous hematologic malignancy that displays diverse responses to chemotherapy. Although a number of clinical factors affect treatment outcomes, the cytogenetic features of AML are generally accepted as strong predictors of therapeutic response (1). Pediatric and adult patients carrying the $t(8 ; 21)$ chromosomal translocation, which is one of the most frequent AML subtypes, are part of a favorable risk group (2). Although these patients are initially highly responsive to treatment, a number of patients relapse and fail to achieve long-term disease-free survival (DFS) (3-5). However, little is currently known concerning the functional mechanism by which $\mathrm{t}(8 ; 21)$ is associated with both a higher remission rate in some patients, and occasionally with poor outcomes in others, except in cases that are characterized by other factors such as distinctive immunophenotypical changes and multidrug resistance genes (6-8).

Cytarabine is a nucleoside analog that is intensively used for the treatment of AML (9-11). Because of its hydrophilic nature, cytarabine can only enter cells via nucleoside transporters such as concentrative nucleoside transporters (CNT1/2/3) and equilibrative nucleoside transporters (ENT1/2) $(12,13)$. Cytarabine must also be converted to its active form by specific enzymes such as deoxycytidine kinase (dCK) (14). Several groups have reported that low gene expression and protein activity of these factors confers resistance to nucleoside drugs of leukemia cells in in vivo and in vitro studies (15-18). Alternatively, activation of certain components of the metabolic machinery such as cytidine deaminase (CDA), ecto-5'-nucleotidase (CD73) and 5',3'-nucleotidase (NT5C), may cause resistance to cytarabine therapy (19-22). Microarray analysis of an in vitro gemcitabine-resistant model revealed upregulation of ribonucleotide reductase $\mathrm{M}$ subunits (RRM1/2) as part of the intracellular detoxification process (23). Nevertheless, the prognostic implications of changes in the expression of these genes have not been elucidated in specific subpopulations, such as in AML patients with $\mathrm{t}(8 ; 21)$. 
In the present study, we hypothesized that specific genes that are closely involved in the antitumor action of cytarabine may be associated with the clinical response to treatment of AML patients carrying $t(8 ; 21)$. Therefore, we attempted to identify a novel marker that was predictive of outcomes of patients carrying the $t(8 ; 21)$ abnormality and evaluated the prognostic impact of the candidate genes.

\section{Materials and methods}

Patient samples. Bone marrow (BM) mononuclear cells (MNCs) from adults newly diagnosed with AML and 4 healthy donors were collected at Chonnam National University Hwasun Hospital and Catholic University Seoul St. Mary's Hospital. Written informed consent for the cryopreservation and use of the samples for further research were obtained from the patients. The Institutional Review Board approved all research on the human subjects participating in the present study. The 54 individuals in the test study and the 44 individuals in the validation study had M2 subtype disease according to the French-American-British (FAB) classification criteria; their clinical information is summarized in Table I. In the test cohort, 16 patients had normal karyotypes, 25 patients had the cytogenetically $t(8 ; 21)$ abnormality, and 13 patients had diverse chromosomal abnormalities. In the validation cohort, 15 patients had normal karyotypes, 19 patients had $\mathrm{t}(8 ; 21)$, and 10 patients had other abnormalities. Intensive remission induction therapy was executed by administration of the combination of $12 \mathrm{mg} / \mathrm{m}^{2} /$ day idarubicin for 3 days with $100 \mathrm{mg} / \mathrm{m}^{2} /$ day cytarabine for 7 days or $N^{4}$-behenoyl-1$D$-arabinofuranosyl cytosine (BH-AC) at either $300 \mathrm{mg} / \mathrm{m}^{2} /$ day for patients younger than 40 years or $200 \mathrm{mg} / \mathrm{m}^{2} /$ day for patients older than 40 years. Four patients received cytarabine alone at a dose of $100 \mathrm{mg} / \mathrm{m}^{2} /$ day; one patient, daunorubicin plus cytarabine; one patient, cytarabine plus etoposide. Patients who failed to achieve complete remission (CR) after the first round of induction chemotherapy received re-induction chemotherapy with the same regimen. Patients achieving a CR received 3 courses of high-dose Ara-C ( $3 \mathrm{~g} / \mathrm{m}^{2}$ every $12 \mathrm{~h} /$ day on days 1, 3 and 5) or the combination of idarubicin and $\mathrm{BH}-\mathrm{AC}$ for consolidation therapy. Thirty-three patients in the test cohort and 13 patients in the validation cohort received hematopoietic stem cell transplantation (HSCT).

RNA preparation and real-time polymerase chain reaction (real-time PCR). Total RNA was extracted from the BM-MNCs of patients using the Qiagen RNA isolation kit (Qiagen, Venlo, The Netherlands) and converted to cDNA with a reverse transcription kit (Invitrogen, Carlsbad, CA, USA). The cDNA was mixed with SYBR-Green PCR Master Mix (PE Applied Biosystems, Foster City, CA, USA) and specific primers for 8 genes including $C D 73, C D A, N T 5 C, d C K, C N T 3, E N T 1$, $R R M 1$ and $R R M 2$. Amplification reactions were performed in triplicate using the ABI Prism 7900 Sequence Detection system (PE Applied Biosystems). GAPDH served as an experimental control. Primer sequences, PCR conditions, and data processing were previously described (24). In the validation study, the expression levels of the membrane transporters, CNT1, CNT2, CNT3, ENT1 and ENT2, were evaluated by the method described above. However, we excluded the results for
Table I. Patient samples.

\begin{tabular}{lcc}
\hline Category & Test & Validation \\
\hline Patients, $\mathrm{n}$ & 54 & 44 \\
Age, median years (range) & $41(20-72)$ & $49(17-73)$ \\
Gender, n (\%) & & \\
Male & $28(51.9)$ & $26(59.1)$ \\
Female & $26(48.1)$ & $18(40.9)$ \\
Blasts, mean \% (range) & $50(2-92)$ & $60(20-91)$ \\
M2 (FAB), n & 54 & 44 \\
Cytogenetics, n & & \\
$\mathrm{t}(8 ; 21)$ & 25 & 19 \\
Normal & 16 & 10 \\
Others & 13 & \\
\hline
\end{tabular}

CNT1 and CNT2 from further analysis because they had low or undetectable signals that were not as reliable.

Survival estimate and correlation analyses. The study population was separated based on the cytogenetic abnormalities of the patients. For the purpose of statistical analysis of the target gene, the patients were also subdivided into 3 groups (low, intermediate and high) according to candidate gene expression tertiles. DFS was defined as the time from first remission to relapse or death. Overall survival (OS) was defined as the time from diagnosis to the date of death or last followup. Kaplan-Meier estimates were used to construct survival curves. Statistical differences in the treatment outcomes were determined by the univariate analyses with log-rank test and Cox proportional hazards univariate model. In multivariate analysis, a backward stepwise method of Cox proportional hazards model was used to investigate the association of clinical variables and gene expression pattern with DFS and OS and to assess hazard ratio (HR) with $95 \%$ confidence interval (CI). Correlations between clinical and molecular features were obtained by Pearson's correlation statistics and represented as a correlation coefficient (r). All statistical analyses were performed using SPSS version 12.0 (SPSS, Inc., Chicago, IL, USA).

\section{Results}

Prolonged survival in patients carrying $t(8 ; 21)$. We collected BM-MNCs from 54 newly diagnosed patients with M2 subtype AML according to the FAB classification who received cytarabine-based chemotherapy. Although it is well established that AML patients with the $t(8 ; 21)$ abnormality respond better to chemotherapy than patients with normal cytogenetics or other cytogenetic abnormalities $(1,2,25)$, we confirmed this in our study population. In a univariate analysis, Kaplan-Meier estimates showed longer survival rates in terms of DFS ( $\mathrm{P}=0.028$ in $\log$-rank; $\mathrm{P}=0.037$ in $\mathrm{Cox}$ model) and $\mathrm{OS}(\mathrm{P}=0.029$ in log-rank; $\mathrm{P}=0.034$ in Cox model $)$ in the $\mathrm{t}(8 ; 21)$-positive AML cohort compared to the $\mathrm{t}(8 ; 21)$ negative group (Fig. 1). 

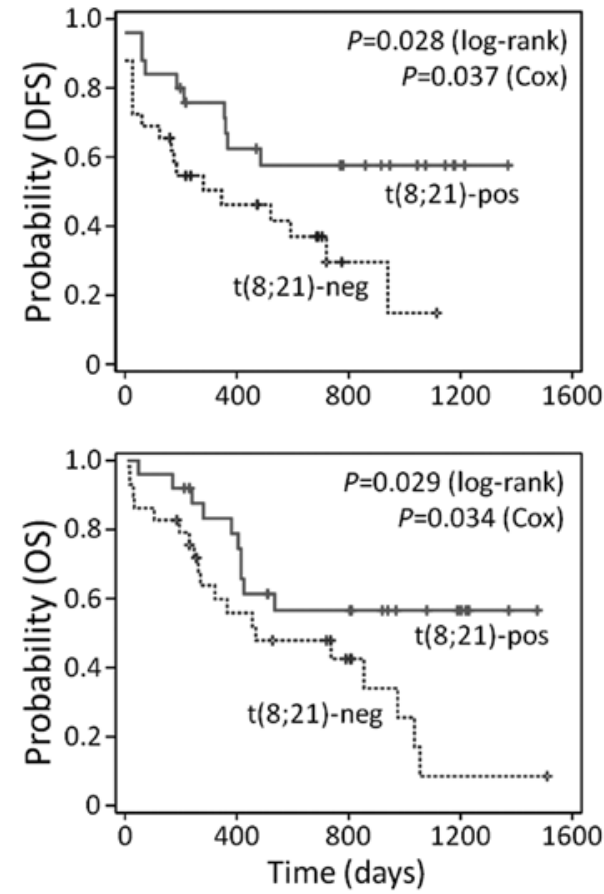

Figure 1. Survival estimate for AML patients who carry or lack the $t(8 ; 21)$ abnormality. Based on cytogenetic abnormalities, 54 patients with acute myeloid leukemia were classified into $t(8 ; 21)$-positive $(n=25)$ and $t(8 ; 21)$ negative $(n=29)$ groups. The curves for DFS and OS were generated using Kaplan-Meier analyses. P-values were obtained using log-rank test and univariate Cox regression analysis.

Elevated CNT3 expression in AML patients with $t(8 ; 21)$. To explore possible pathological reasons for the better response to cytarabine-based therapy in $\mathrm{t}(8 ; 21)$-positive patients, we examined the mRNA expression levels of 8 candidate genes in a total of $54 \mathrm{AML}$ patients. These genes included $C D 73$, $C D A, N T 5 C, d C K, C N T 3, E N T 1, R R M 1$ and RRM2, which are genes that are closely involved in metabolic processing of nucleoside analogs. Of the 8 genes, only CNT3 mRNA levels were significantly different between the $t(8 ; 21)$-positive and -negative patients in non-parametric statistical analysis with Mann-Whitney $\mathrm{U}$ test $(\mathrm{P}<0.001)$; no significant differences were observed for the remaining genes (Fig. 2A). Using the level of $C N T 3$ in the healthy donors as a reference, the median expression values were 1.89 (range, $0.36-7.67$ ) for $\mathrm{t}(8 ; 21)$-positive patients and 0.63 (range, $0.05-2.16$ ) for $\mathrm{t}(8 ; 21)$-negative patients. For the study of correlation between expression patterns of the candidate genes and cytogenetic characteristics of the patients, we conducted Pearson's correlation analysis. This analysis revealed that only the CNT3 level had a definite correlation with the presence of cytogenetic abnormalities $(r=0.520 ; \mathrm{P}<0.001)$ (at bottom in Fig. 2A).

To further clarify the distinctive expression patterns of $C N T 3$ in patients, we divided the patients into 3 groups: $\mathrm{t}(8 ; 21)(\mathrm{n}=25)$, normal cytogenetics $(\mathrm{n}=16)$, and other cytogenetic abnormalities $(\mathrm{n}=13)$. The patients carrying $\mathrm{t}(8 ; 21)$ still had higher $C N T 3$ expression compared to either of the other patient groups, even though the $t(8 ; 21)$-negative population was divided into 2 subpopulations (Fig. 2B).

The $\mathrm{t}(8 ; 21)$ abnormality-specific increase in $C N T 3$ expression was confirmed in a validation cohort of 44 patients diagnosed with M2 FAB subtype AML. To further examine the association between nucleoside transporter genes and cytogenetic abnormalities, we analyzed expression levels of solute carrier (SLC) family genes, including SLC28 (CNT1, CNT2 and $C N T 3$ ) and SLC29 (ENT1 and ENT2). The levels of CNT1 and $C N T 2$ mRNA were low or undetectable in most of the validation cohort and, therefore, results for these genes were excluded from the following analysis. As shown in Fig. 3A, we observed that $C N T 3$ expression was significantly elevated in patient samples that were $t(8 ; 21)$-positive, compared to those that were $t(8 ; 21)$-negative $(\mathrm{P}<0.001$ in $\mathrm{U}$ test and $\mathrm{P}=0.002$ in Pearson's correlation statistics). The median expression values were 2.23 (range, 0.39 -15.76) for $\mathrm{t}(8 ; 21)$-positive patients and
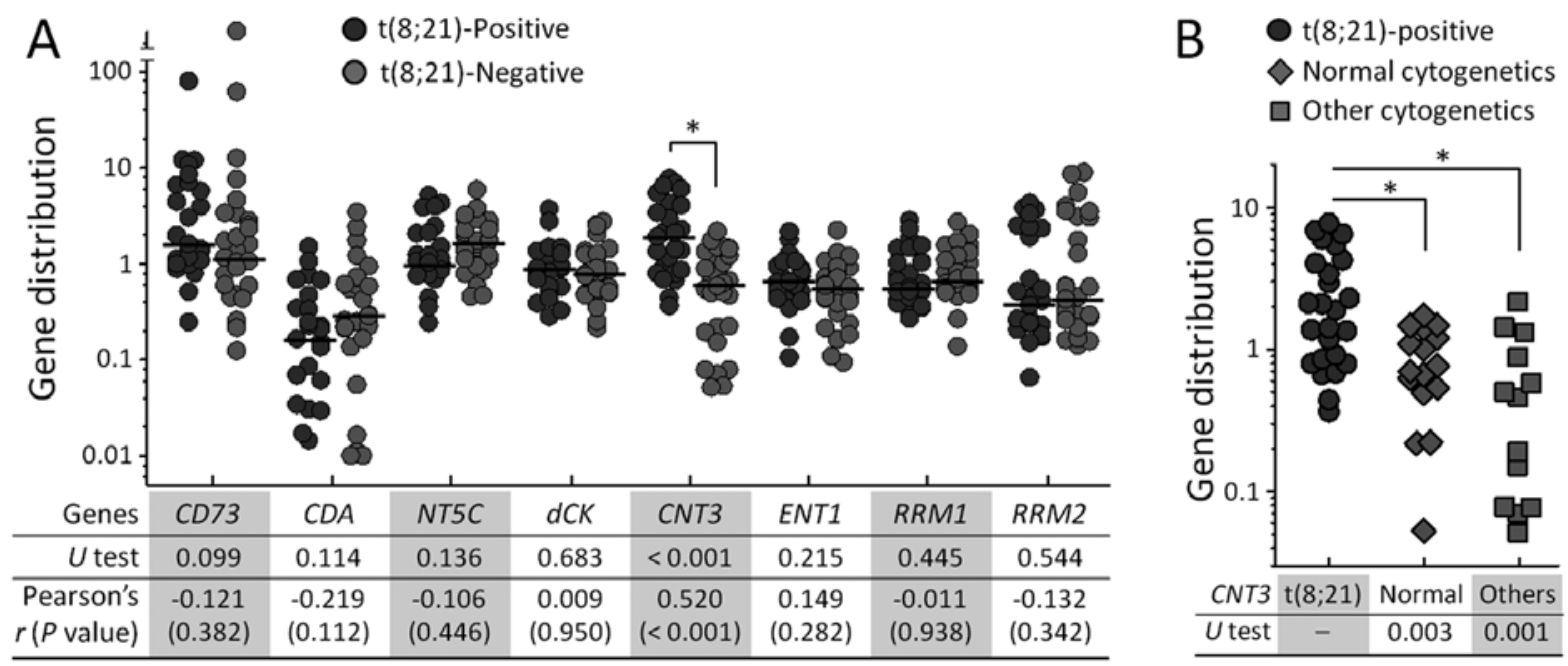

Figure 2. Gene distribution in AML patients who carry or lack the $t(8 ; 21)$ abnormality. (A) Expression levels of 8 genes in 54 AML patients were normalized by comparison to the mean expression values in 4 healthy donors. Values are displayed separately according to the presence $(n=25)$ or absence $(n=29)$ of the $\mathrm{t}(8 ; 21)$ abnormality. The solid lines denote the median levels in each population. (B) To further compare CNT3 expression in detail, patients were subdivided into 3 groups: patients with normal cytogenetics, $\mathrm{t}(8 ; 21)$-positive patients, and patients with other cytogenetic abnormalities. The statistical differences were estimated by Mann-Whitney U tests. The association between gene expression pattern and cytogenetic status was determined using Pearson's correlation analysis. r, correlation coefficient. 

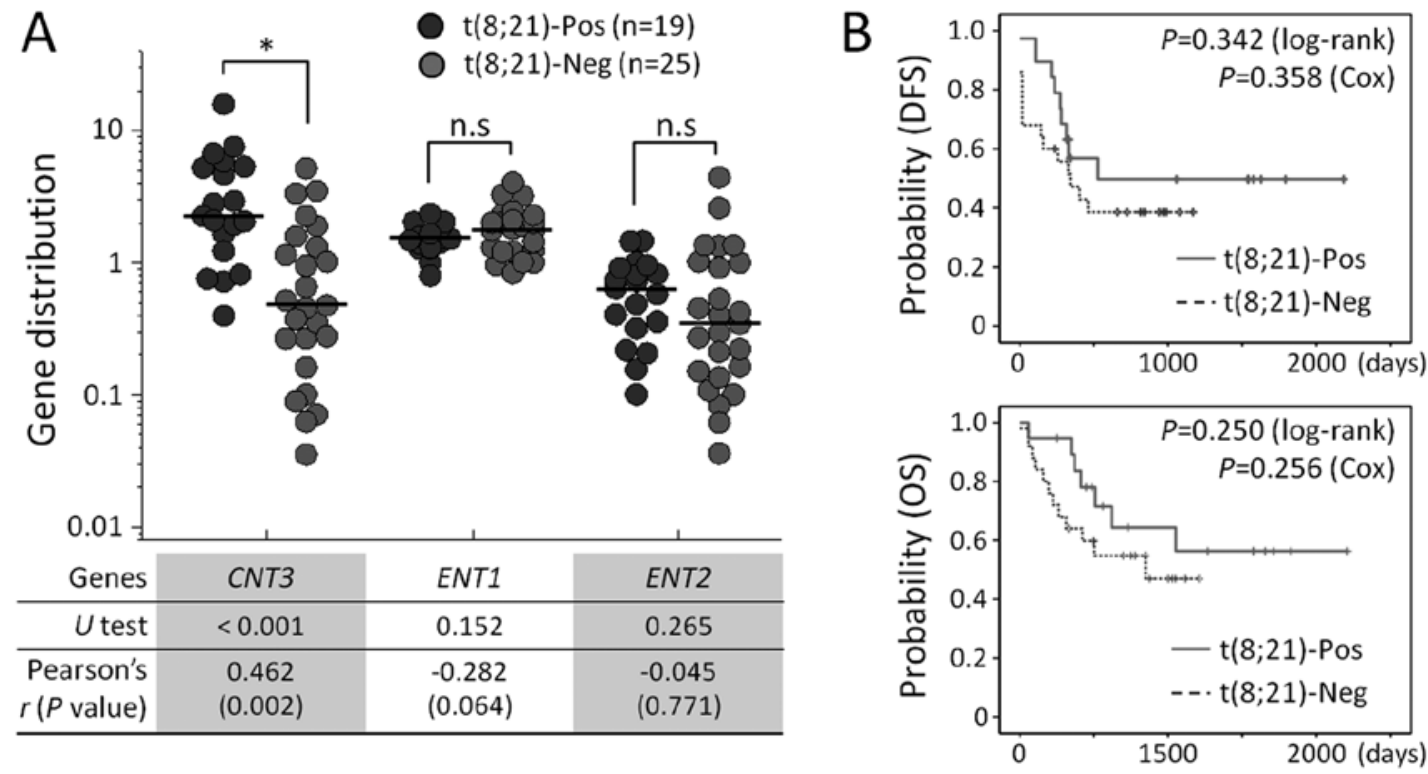

Figure 3. Distribution of nucleoside transporters in the validation population. (A) Expression levels of nucleoside membrane transporters were measured in 44 patients by real-time PCR. Values are presented according to the presence or absence of the $t(8 ; 21)$ abnormality. The solid lines denote the median levels of each gene in the indicated populations. The statistical differences were calculated by Mann-Whitney U tests. The association between the gene expression pattern and the cytogenetic status was determined using Pearson's correlation analysis. r, correlation coefficient. n.s, not significant. (B) The validation cohort was divided into a $\mathrm{t}(8 ; 21)$-positive group $(\mathrm{n}=19)$ and a $\mathrm{t}(8 ; 21)$-negative group $(\mathrm{n}=25)$. The curves for DFS and OS were generated using Kaplan-Meier analyses. $\mathrm{P}$-values were obtained using log-rank tests and univariate Cox regression analysis.
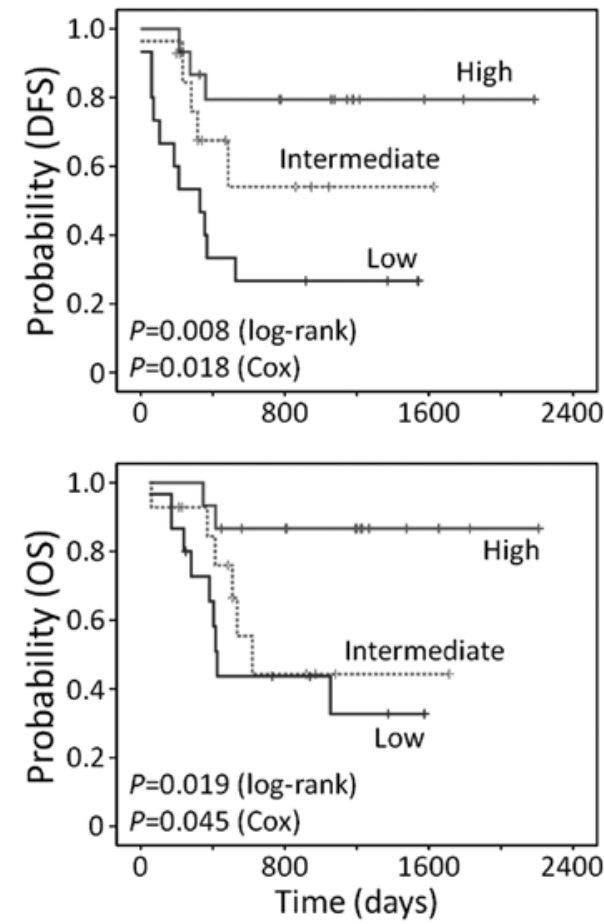

Figure 4. Prognostic value of $C N T 3$ in AML patients with $\mathrm{t}(8 ; 21)$. The 44 $\mathrm{t}(8 ; 21)$-positive patients from the test cohort and the validation cohort were divided into tertiles based on the $C N T 3$ expression level: low $(\mathrm{n}=15 ; C N T 3$ $<1.34$ ), intermediate ( $\mathrm{n}=14 ; C N T 3 \geq 1.34$ and $<3.37)$, and high ( $\mathrm{n}=15 ;$; $C N T 3$ 23.37). The curves for DFS and OS were generated using Kaplan-Meier estimates. P-values were determined using log-rank tests and univariate Cox regression analysis.

0.47 (0.04-5.12) for $\mathrm{t}(8 ; 21)$-negative patients. Levels of ENT1 and ENT2 were not statistically different between the two groups. We also compared DFS and OS between $\mathrm{t}(8 ; 21)$ - positive and -negative patient groups. Prolonged survival was observed in patients harboring $\mathrm{t}(8 ; 21)$, although the results did not reach statistical significance for survival indices $(\mathrm{P}=0.342$ for DFS and $\mathrm{P}=0.250$ for OS in log-rank tests; Fig. $3 \mathrm{~B})$. The $\mathrm{t}(8 ; 21)$-specific higher expression of CNT3 was consistent with the observation in Fig. 2 and implies a particular contribution of CNT3 to favorable outcomes of these patients.

Prognostic impact of CNT3 expression on treatment outcomes. We hypothesized that expression of CNT3 in patients with $\mathrm{t}(8 ; 21)$ could enable more precise prediction of treatment outcomes. To examine the potential role of CNT3 in predicting outcomes, $45 \mathrm{t}(8 ; 21)$-positive patients from the test and validation cohorts were clustered into 3 groups (tertiles) based on their levels of CNT3 expression (high, intermediate or low). First, the prognostic impact of CNT3 was evaluated by univariate analysis. As shown in Fig. 4, patients with high CNT3 expression had significantly longer survival compared to the other two patient groups (DFS, $\mathrm{P}=0.008$; OS, $\mathrm{P}=0.019$ in log-rank tests). In a Cox proportional hazards univariate model, HRs for the patients in the high CNT3 tertile compared to the patients in the low tertile were 0.18 (95\% CI, 0.05-0.63; $\mathrm{P}=0.008)$ for DFS and 0.14 (95\% CI, 0.03-0.66; $\mathrm{P}=0.013)$ for OS. However, when the prognostic value of CNT3 was investigated in a separate, restricted group of patients lacking the $\mathrm{t}(8 ; 21)$, there were no significant differences in survival among the subpopulations with different $C N T 3$ expression levels (data not shown).

We conducted a multivariate analysis using the Cox proportional hazards model, which adjusted for the influence of the remission induction (RI) regimen, hematopoietic stem cell transplantation (HSCT), blast percentage, age, gender and CNT3 mRNA; this model confirmed that high CNT3 expression 
Table II. Multivariate analysis of clinical outcomes in the $t(8 ; 21)$-positive patients.

\begin{tabular}{|c|c|c|c|c|}
\hline \multirow[b]{2}{*}{ Variable } & \multicolumn{2}{|c|}{ Disease-free survival } & \multicolumn{2}{|c|}{ Overall survival } \\
\hline & $\mathrm{HR}(95 \% \mathrm{CI})$ & P-value & $\mathrm{HR}(95 \% \mathrm{CI})$ & P-value \\
\hline \multicolumn{5}{|l|}{ CNT3 expression } \\
\hline CNT3 <1.34 (n=15) & 1 (reference) & & 1 (reference) & \\
\hline$C N T 3 \geq 1.34$ and $<3.37(\mathrm{n}=14)$ & $0.44(0.14-1.38)$ & 0.158 & $0.80(0.24-2.64)$ & 0.717 \\
\hline CNT3 $\geq 3.37(\mathrm{n}=15)$ & $0.12(0.03-0.56)$ & 0.007 & $0.06(0.01-0.52)$ & 0.010 \\
\hline \multicolumn{5}{|l|}{ RI regimen } \\
\hline Ida/AraC $(\mathrm{n}=24)$ & 1 (reference) & & 1 (reference) & \\
\hline Ida/BHAC (n=20) & $1.11(0.36-3.45)$ & 0.860 & $2.20(0.67-7.23)$ & 0.196 \\
\hline \multicolumn{5}{|l|}{ HSCT } \\
\hline Yes $(n=24)$ & 1 (reference) & & 1 (reference) & \\
\hline No $(n=20)$ & $1.27(0.45-3.59)$ & 0.658 & $1.66(0.51-5.39)$ & 0.401 \\
\hline \multicolumn{5}{|l|}{ Blast (\%) } \\
\hline$<50(\mathrm{n}=16)$ & 1 (reference) & & 1 (reference) & \\
\hline$\geq 50(n=27)$ & $0.47(0.14-1.56)$ & 0.214 & $0.46(0.12-1.72)$ & 0.251 \\
\hline \multicolumn{5}{|l|}{ Age (years) } \\
\hline$\leq 60(n=39)$ & 1 (reference) & & 1 (reference) & \\
\hline$>60(\mathrm{n}=5)$ & $0.54(0.11-2.53)$ & 0.431 & $0.69(0.14-3.51)$ & 0.654 \\
\hline \multicolumn{5}{|l|}{ Gender } \\
\hline Male $(n=26)$ & 1 (reference) & & 1 (reference) & \\
\hline Female $(n=18)$ & $1.37(0.46-4.14)$ & 0.573 & $1.80(0.52-6.27)$ & 0.355 \\
\hline
\end{tabular}

HR, hazard ratio; CI, confidence interval; RI, remission induction; HSCT, hematopoietic stem cell transplantation.

was an independent risk factor associated with DFS (HR, 0.12; $\mathrm{P}=0.007)$ and $\mathrm{OS}(\mathrm{HR}, 0.06 ; \mathrm{P}=0.010)$ (Table II). Alternatively, clinical outcomes of patients with $\mathrm{t}(8 ; 21)$-negative AML were affected by the RI regimen and HSCT, but not by the CNT3 expression status (data not shown). These findings suggest that CNT3 expression levels can be used to stratify overall clinical outcomes after cytarabine-based standard chemotherapy in AML patients with $\mathrm{t}(8 ; 21)$.

\section{Discussion}

We showed that cytogenetic abnormality-specific expression of CNT3 in leukemic blasts from AML patients correlated with favorable responses to cytarabine-based chemotherapy and prolonged survival of patients with $t(8 ; 21)$. We also found that $C N T 3$ expression level was an independent predictor of the response to cytarabine-based chemotherapy in the $t(8 ; 21)$ positive AML patients.

The $t(8 ; 21)$ translocation is one of the most frequent cytogenetic abnormalities, occurring in a large proportion (up to $15 \%$ ) of AML patients. This type of AML has a high remission rate to chemotherapy, particularly when high-dose cytarabine is administered $(2,9,26)$. Nevertheless, some patients with $t(8 ; 21)$ experience relapse and fail to maintain long-term survival (3-5). For this reason, most studies concerning the treatment response in AML with $\mathrm{t}(8 ; 21)$ have been devoted to identification of useful markers that can be measured at diagnosis to predict poor outcomes. Representative clinically significant examples include the association of natural killer cell antigen CD56 and P-glycoprotein with inferior outcomes in $\mathrm{t}(8 ; 21)$-positive AML patients $(6-8,27)$. However, neither of these factors is linked with favorable outcomes in patients carrying this aberration. Although a limited number of patients were examined in the present study, we were able to provide the first example of a gene related to cytarabine metabolism that can explain the varied responses of these patients to cytarabine therapy.

Nucleoside transporters including both influx and efflux pumps and drug metabolism-associated enzymes have been steadily identified as predictive markers of clinical outcomes and as potential therapeutic targets (24,28-31). In this study, we examined two types of specialized influx pumps of nucleoside analogs, ENTs and CNTs, as potential candidates for predicting patient outcomes. We chose these transporters because of previous reports indicating that they have a broad spectrum of substrate flux and are predominantly expressed in BM cells (32-34). CNT3 expression significantly correlated with the presence of the $t(8 ; 21)$ aberration in both the test and validation data sets. Previous reports indicated that ENT1 was clinically significant for cytarabine-mediated therapy; however, the present study found a slight but insignificant correlation between ENT1 and the $\mathrm{t}(8 ; 21)$ translocation in 
correlation analysis and survival analysis in AML patients with $\mathrm{t}(8 ; 21)(33,35,36)$. These results indicate that $C N T 3$, but not ENT1 or other functional genes, is a specific marker of cytogenetics in AML and is also a critical factor in the responsiveness of $\mathrm{t}(8 ; 21)$-positive patients to cytarabine.

Nucleoside transporters are required not only for nucleotide synthesis, but also for import of a variety of nucleoside-derived anticancer drugs. Specifically, CNT3 plays a role in the uptake of a broad range of nucleosides and their analogs, while CNT1 and CNT2 are responsible for specialized substrates (pyrimidine and purine nucleosides for CNT1 and CNT2, respectively) (34). Most studies that have only analyzed CNT3 have used in vitro assays to identify a critical role of CNT3 in the antitumor effect of nucleoside drugs and the resistance to these drugs $(34,37,38)$. Alternatively, a study by Mackey et al (30) showed a negative correlation between CNT3 and clinical outcomes after fludarabine therapy in patients with chronic lymphocytic leukemia. Furthermore, distinct expression of CNT3 has not been reported in AML with specific cytogenetics, even though there were several genome-wide approaches to dissect gene profiles in large numbers of patients (39-41). The present study is the first to demonstrate that $C N T 3$ levels can be used to stratify patients based on survival outcomes in, at least in part, $\mathrm{t}(8 ; 21)$-positive but not $\mathrm{t}(8 ; 21)$-negative AML patients. We questioned why the prognostic potential of $C N T 3$ preferentially applied to $t(8 ; 21)$ positive AML patients. For the survival analysis, we divided $\mathrm{t}(8 ; 21)$-positive or -negative patients into subpopulations based on their CNT3 expression level. The median values for CNT3 expression were 2.07 (range, $0.36-15.76$ ) for the $t(8 ; 21)$-positive cohort and 0.56 (range, 0.04-5.12) for the $t(8 ; 21)$-negative cohort. One potential explanation for this observation is that, at least in the $t(8 ; 21)$-negative population, the small range of CNT3 expression might be insufficient to allow stratification for outcome prediction. Although we did not determine whether $C N T 3$ transcript levels were consistent with protein expression levels in individual patients, and we did not ensure that the protein encoded by the CNT3 gene was functional, it is believed that low mRNA levels are indicative of low CNT3 protein levels, which are insufficient for CNT3 to carry out its novel function.

In the CNT nucleoside transporter family, expression levels of CNT1 and CNT2 are known to be upregulated by extracellular stimuli including cell proliferation and activation (42-44). However, the mechanism of transcriptional regulation of $C N T 3$ remains largely unknown. Based on our novel finding that CNT3 was upregulated in AML patients with $t(8 ; 21)$ but not in patients with other cytogenetic changes, we hypothesize that there may be a physiological interaction between the AML1 or AML1-ETO chimera proteins, which are derived from the $t(8 ; 21)$ translocation, and the promoter region of $C N T 3$. Indeed, a virtual analysis for promoter prediction performed using transcription factor binding site search software identified 3 putative binding sites for AML1 at -3438 to $-3433,-888$ to -883 , and +526 to +531 relative to the transcription start site of CNT3. Therefore, additional study is necessary to identify a role of these putative binding sites.

In summary, our results imply that higher CNT3 expression in AML patients with $\mathrm{t}(8 ; 21)$ contributes to the prolonged survival observed in this population. Our results also suggest that CNT3 can be used to predict clinical responses to cytarabine-based therapies in AML patients with $\mathrm{t}(8 ; 21)$.

\section{Acknowledgements}

The present study was supported by grant A111218-GM06 of the National Project for Personalized Genomic Medicine, Ministry for Health and Welfare, the National Research Foundation of Korea (NRF) grant 2011-0001388 funded by the Korean government and a Korea University grant.

\section{References}

1. Grimwade D, Walker H, Oliver F, Wheatley K, Harrison C, Harrison G, Rees J, Hann I, Stevens R, Burnett A, et al; The Medical Research Council Adult and Children's Leukaemia Working Parties: The importance of diagnostic cytogenetics on outcome in AML: Analysis of 1,612 patients entered into the MRC AML 10 trial. Blood 92: 2322-2333, 1998.

2. Estey EH: Acute myeloid leukemia: 2012 update on diagnosis, risk stratification, and management. Am J Hematol 87: 89-99, 2012.

3. Bloomfield CD, Herzig GP, Peterson BA and Wolff SN: Long-term survival of patients with acute myeloid leukemia: Updated results from two trials evaluating postinduction chemotherapy. Cancer 80 (Suppl): 2186-2190, 1997.

4. O'Brien S, Kantarjian HM, Keating M, Gagnon G, Cork A, Trujillo J and McCredie KB: Association of granulocytosis with poor prognosis in patients with acute myelogenous leukemia and translocation of chromosomes 8 and 21. J Clin Oncol 7: 1081-1086, 1989.

5. Prébet T, Boissel N, Reutenauer S, Thomas X, Delaunay J, Cahn JY, Pigneux A, Quesnel B, Witz F, Thépot S, et al; Acute Leukemia French Association; Groupe Ouest-Est des leucémies et autres maladies du sang (GOELAMS); Core Binding Factor Acute Myeloid Leukemia (CBF AML) intergroup: Acute myeloid leukemia with translocation $(8 ; 21)$ or inversion (16) in elderly patients treated with conventional chemotherapy: A collaborative study of the French CBF-AML intergroup. J Clin Oncol 27: 4747-4753, 2009.

6. Baer MR, Stewart CC, Lawrence D, Arthur DC, Byrd JC, Davey FR, Schiffer CA and Bloomfield CD: Expression of the neural cell adhesion molecule CD56 is associated with short remission duration and survival in acute myeloid leukemia with $\mathrm{t}(8 ; 21)(\mathrm{q} 22 ; \mathrm{q} 22)$. Blood 90: 1643-1648, 1997.

7. Schaich M, Koch R, Soucek S, Repp R, Ehninger G and Illmer T: A sensitive model for prediction of relapse in adult acute myeloid leukaemia with $\mathrm{t}(8 ; 21)$ using white blood cell count, CD56 and MDR1 gene expression at diagnosis. Br J Haematol 125: 477-479, 2004.

8. Yang DH, Lee JJ, Mun YC, Shin HJ, Kim YK, Cho SH, Chung IJ, Seong CM and Kim HJ: Predictable prognostic factor of CD56 expression in patients with acute myeloid leukemia with $\mathrm{t}(8: 21)$ after high dose cytarabine or allogeneic hematopoietic stem cell transplantation. Am J Hematol 82: 1-5, 2007.

9. Bloomfield CD, Lawrence D, Byrd JC, Carroll A, Pettenati MJ, Tantravahi R, Patil SR, Davey FR, Berg DT, Schiffer CA, et al: Frequency of prolonged remission duration after high-dose cytarabine intensification in acute myeloid leukemia varies by cytogenetic subtype. Cancer Res 58: 4173-4179, 1998.

10. Weick JK, Kopecky KJ, Appelbaum FR, Head DR, Kingsbury LL, Balcerzak SP, Bickers JN, Hynes HE, Welborn JL, Simon SR, et al: A randomized investigation of high-dose versus standarddose cytosine arabinoside with daunorubicin in patients with previously untreated acute myeloid leukemia: A Southwest Oncology Group study. Blood 88: 2841-2851, 1996.

11. Schnetzke U, Fix P, Spies-Weisshart B, Schrenk K, Glaser A, Fricke HJ, La Rosée P, Hochhaus A and Scholl S: Efficacy and feasibility of cyclophosphamide combined with intermediate- dose or high-dose cytarabine for relapsed and refractory acute myeloid leukemia (AML). J Cancer Res Clin Oncol 140: 1391-1397, 2014.

12. Damaraju VL, Damaraju S, Young JD, Baldwin SA, Mackey J, Sawyer MB and Cass CE: Nucleoside anticancer drugs: The role of nucleoside transporters in resistance to cancer chemotherapy. Oncogene 22: 7524-7536, 2003. 
13. Zhang J, Visser F, King KM, Baldwin SA, Young JD and Cass CE The role of nucleoside transporters in cancer chemotherapy with nucleoside drugs. Cancer Metastasis Rev 26: 85-110, 2007.

14. Momparler RL and Fischer GA: Mammalian deoxynucleoside kinase. I. Deoxycytidine kinase: Purification, properties, and kinetic studies with cytosine arabinoside. J Biol Chem 243 4298-4304, 1968.

15. Galmarini CM, Thomas X, Graham K, El Jafaari A, Cros E, Jordheim L, Mackey JR and Dumontet C: Deoxycytidine kinase and $\mathrm{cN}$-II nucleotidase expression in blast cells predict survival in acute myeloid leukaemia patients treated with cytarabine. Br J Haematol 122: 53-60, 2003.

16. Molina-Arcas M, Bellosillo B, Casado FJ, Montserrat E, Gil J, Colomer D and Pastor-Anglada M: Fludarabine uptake mechanisms in B-cell chronic lymphocytic leukemia. Blood 101: 2328-2334, 2003.

17. Song JH, Kim SH, Kweon SH, Lee TH, Kim HJ, Kim HJ and Kim TS: Defective expression of deoxycytidine kinase in cytarabine-resistant acute myeloid leukemia cells. Int J Oncol 34: $1165-1171,2009$

18. Takagaki K, Katsuma S, Kaminishi Y, Horio T, Nakagawa S Tanaka T, Ohgi T and Yano J: Gene-expression profiling reveals down-regulation of equilibrative nucleoside transporter 1 (ENT1) in Ara-C-resistant CCRF-CEM-derived cells. J Biochem 136 733-740, 2004

19. Abraham A, Varatharajan S, Abbas S, Zhang W, Shaji RV, Ahmed R, Abraham A, George B, Srivastava A, Chandy M, et al: Cytidine deaminase genetic variants influence RNA expression and cytarabine cytotoxicity in acute myeloid leukemia. Pharmacogenomics 13: 269-282, 2012.

20. Galmarini CM, Cros E, Graham K, Thomas X, Mackey JR and Dumontet C: $5^{\prime}-\left(3^{\prime}\right)$-nucleotidase mRNA levels in blast cells are a prognostic factor in acute myeloid leukemia patients treated with cytarabine. Haematologica 89: 617-619, 2004.

21. Momparler RL, Eliopoulos N, Bovenzi V, Létourneau S, Greenbaum $M$ and Cournoyer D: Resistance to cytosine arabinoside by retrovirally mediated gene transfer of human cytidine deaminase into murine fibroblast and hematopoietic cells. Cancer Gene Ther 3: 331-338, 1996.

22. Ujházy P, Berleth ES, Pietkiewicz JM, Kitano H, Skaar JR, Ehrke MJ and Mihich E: Evidence for the involvement of ecto-5'-nucleotidase (CD73) in drug resistance. Int J Cancer 68 : 493-500, 1996

23. Smid K, Bergman AM, Eijk PP, Veerman G, van Haperen VW, van den Ijssel P, Ylstra B and Peters GJ: Micro-array analysis of resistance for gemcitabine results in increased expression of ribonucleotide reductase subunits. Nucleosides Nucleotides Nucleic Acids 25: 1001-1007, 2006.

24. Song JH, Kweon SH, Kim HJ, Lee TH, Min WS, Kim HJ, Kim YK, Hwang SY and Kim TS: High TOP2B/TOP2A expression ratio at diagnosis correlates with favourable outcome for standard chemotherapy in acute myeloid leukaemia. Br J Cancer 107: 108-115, 2012.

25. Cho EK, Bang SM, Ahn JY, Yoo SM, Park PW, Seo YH, Shin DB and Lee JH: Prognostic value of AML 1/ETO fusion transcripts in patients with acute myelogenous leukemia. Korean J Intern Med 18: 13-20, 2003

26. Downing JR: The AML1-ETO chimaeric transcription factor in acute myeloid leukaemia: Biology and clinical significance. Br J Haematol 106: 296-308, 1999.

27. Schaich M, Harbich-Brutscher E, Pascheberg U, Mohr B, Soucek S, Ehninger G and Illmer T: Association of specific cytogenetic aberrations with mdrl gene expression in adult myeloid leukemia and its implication in treatment outcome. Haematologica 87: 455-464, 2002.

28. Jin G, Matsushita H, Asai S, Tsukamoto H, Ono R, Nosaka T, Yahata T, Takahashi S and Miyachi H: FLT3-ITD induces ara-C resistance in myeloid leukemic cells through the repression of the ENT1 expression. Biochem Biophys Res Commun 390: 1001-1006, 2009.

29. Jordheim LP and Dumontet C: Review of recent studies on resistance to cytotoxic deoxynucleoside analogues. Biochim Biophys Acta 1776: 138-159, 2007

30. Mackey JR, Galmarini CM, Graham KA, Joy AA, Delmer A, Dabbagh L, Glubrecht D, Jewell LD, Lai R, Lang T, et al: Quantitative analysis of nucleoside transporter and metabolism gene expression in chronic lymphocytic leukemia (CLL) Identification of fludarabine-sensitive and -insensitive populations. Blood 105: 767-774, 2005
31. Guo Y, Köck K, Ritter CA, Chen ZS, Grube M, Jedlitschky G, Illmer T, Ayres M, Beck JF, Siegmund W, et al: Expression of ABCC-type nucleotide exporters in blasts of adult acute myeloid leukemia: Relation to long-term survival. Clin Cancer Res 15: $1762-1769,2009$.

32. Griffiths M, Beaumont N, Yao SY, Sundaram M, Boumah CE, Davies A, Kwong FY, Coe I, Cass CE, Young JD, et al: Cloning of a human nucleoside transporter implicated in the cellular uptake of adenosine and chemotherapeutic drugs. Nat Med 3: 89-93, 1997.

33. Hubeek I, Stam RW, Peters GJ, Broekhuizen R, Meijerink JP, van Wering ER, Gibson BE, Creutzig U, Zwaan CM, Cloos J, et al: The human equilibrative nucleoside transporter 1 mediates in vitro cytarabine sensitivity in childhood acute myeloid leukaemia. Br J Cancer 93: 1388-1394, 2005.

34. Ritzel MW, Ng AM, Yao SY, Graham K, Loewen SK, Smith KM, Ritzel RG, Mowles DA, Carpenter P, Chen XZ, et al: Molecular identification and characterization of novel human and mouse concentrative $\mathrm{Na}^{+}$-nucleoside cotransporter proteins (hCNT3 and mCNT3) broadly selective for purine and pyrimidine nucleosides (system cib). J Biol Chem 276: 2914-2927, 2001.

35. Galmarini CM, Thomas X, Calvo F, Rousselot P, El Jafaari A, Cros E and Dumontet C: Potential mechanisms of resistance to cytarabine in AML patients. Leuk Res 26: 621-629, 2002.

36. Stam RW, den Boer ML, Meijerink JP, Ebus ME, Peters GJ, Noordhuis P, Janka-Schaub GE, Armstrong SA, Korsmeyer SJ and Pieters R: Differential mRNA expression of Ara-Cmetabolizing enzymes explains Ara-C sensitivity in MLL gene-rearranged infant acute lymphoblastic leukemia. Blood 101: 1270-1276, 2003

37. Fotoohi AK, Lindqvist M, Peterson $\mathrm{C}$ and Albertioni F: Involvement of the concentrative nucleoside transporter 3 and equilibrative nucleoside transporter 2 in the resistance of T-lymphoblastic cell lines to thiopurines. Biochem Biophys Res Commun 343: 208-215, 2006.

38. Karim H, Hashemi J, Larsson C, Moshfegh A, Fotoohi AK and Albertioni F: The pattern of gene expression and gene dose profiles of 6-Mercaptopurine- and 6-Thioguanine-resistant human leukemia cells. Biochem Biophys Res Commun 411: 156-161, 2011.

39. Verhaak RG, Wouters BJ, Erpelinck CA, Abbas S, Beverloo HB, Lugthart S, Löwenberg B, Delwel R and Valk PJ: Prediction of molecular subtypes in acute myeloid leukemia based on gene expression profiling. Haematologica 94: 131-134, 2009.

40. Balgobind BV, Van den Heuvel-Eibrink MM, De Menezes RX, Reinhardt D, Hollink IH, Arentsen-Peters ST, van Wering ER, Kaspers GJ, Cloos J, de Bont ES, et al: Evaluation of gene expression signatures predictive of cytogenetic and molecular subtypes of pediatric acute myeloid leukemia. Haematologica 96: 221-230, 2011.

41. Ichikawa H, Tanabe K, Mizushima H, Hayashi Y, Mizutani S, Ishii E, Hongo T, Kikuchi A and Satake M: Common gene expression signatures in $\mathrm{t}(8 ; 21)$ - and inv(16)-acute myeloid leukaemia. Br J Haematol 135: 336-347, 2006.

42. Duflot S, Riera B, Fernández-Veledo S, Casadó V, Norman RI, Casado FJ, Lluís C, Franco R and Pastor-Anglada M: ATP-sensitive $\mathrm{K}^{+}$channels regulate the concentrative adenosine transporter CNT2 following activation by $\mathrm{A}_{1}$ adenosine receptors. Mol Cell Biol 24: 2710-2719, 2004.

43. Fernández-Veledo S, Valdés R, Wallenius V, Casado FJ and Pastor-Anglada M: Up-regulation of the high-affinity pyrimidine-preferring nucleoside transporter concentrative nucleoside transporter 1 by tumor necrosis factor-alpha and interleukin- 6 in liver parenchymal cells. J Hepatol 41: 538-544, 2004.

44. Soler C, Felipe A, García-Manteiga J, Serra M, Guillén-Gómez E, Casado FJ, MacLeod C, Modolell M, Pastor-Anglada M and Celada A: Interferon-gamma regulates nucleoside transport systems in macrophages through signal transduction and activator of transduction factor 1 (STAT1)-dependent and -independent signalling pathways. Biochem J 375: 777-783, 2003. 